\title{
EDUCAÇÃO ESTATÍSTICA NOS ANOS INICIAIS DO ENSINO FUNDAMENTAL
}

\author{
EDUCACIÓN ESTADÍSTICA EN LOS AÑOS INICIALES \\ DE LA ENSEÑANZA PRIMARIA
}

\section{STATISTICAL EDUCATION IN THE EARLY YEARS OF ELEMENTARY EDUCATION}

\author{
Thays Votto \\ Mestranda em Educação em Ciências pela Universidade Federal do Rio Grande (FURG). \\ Rio Grande-RS, Brasil. \\ thayvotto@hotmail.com \\ Karla Priscila Schreiber \\ Doutoranda em Educação em Ciências Universidade Federal do Rio Grande (FURG) \\ Rio Grande-RS, Brasil. \\ karla.pschereiber@hotmail.com \\ Mauren Porciúncula \\ Professora Doutora da Universidade Federal do Rio Grande (FURG) \\ Rio Grande-RS, Brasil. \\ mauren@furg.br
}

Resumo: Este estudo, de caráter metodológico qualitativo-quantitativo, caracteriza-se como uma pesquisa piloto da dissertação de mestrado da primeira autora. O objetivo geral da pesquisa é compreender quais habilidades referentes à Estatística estão sendo desenvolvidas nos Anos Iniciais do Ensino Fundamental. Estas estão preconizadas nos documentos oficiais que norteiam a Educação neste nível de ensino. Para tanto, realizou-se uma revisão de literatura do tipo Estado do Conhecimento. Participaram da pesquisa quantitativa 12 professores deste nível de ensino que lecionam em uma escola da rede municipal de Rio Grande/RS. O procedimento utilizado para a coleta de dados consistiu da aplicação de um questionário que abrangeu questões relacionadas à formação inicial e continuada dos professores, tempo de serviço docente, e as disciplinas de Estatística cursadas durante a graduação. Ainda continha uma lista de habilidades preconizadas nos Parâmetros Curriculares Nacionais (PCNs) e na Base Nacional Comum Curricular (BNCC), na qual os professores deveriam elencar quais estão desenvolvendo em sua prática pedagógica. Para a análise dos dados, utilizou-se a Estatística Descritiva. Os resultados demonstram que as habilidades desenvolvidas com maior frequência, indicadas pelos próprios professores sujeitos da pesquisa são: interpretação de informações contidas em imagens, interpretação de tabelas e gráficos e coleta e organização de informações. Diante dos resultados dessa pesquisa, percebe-se que maior ênfase vem sendo atribuída à Estatística Descritiva, em comparação com o ciclo investigativo de uma pesquisa, corroborando os achados da revisão de Estado do Conhecimento.

Palavras-chave: Educação Estatística. Habilidades. Anos Iniciais do Ensino Fundamental.

\begin{abstract}
This study of qualitative and quantitative methodological character is characterized as a pilot research of the dissertation of the first author. The general objective of the research is to understand which skills related to Statistics are being developed in the Early Years of Elementary Education. These are advocated in the official documents that guide Education at this level of education. For this a literature review of the State of Knowledge type was carried out. Participated in the quantitative research twelve teachers of this level of education who teach in a municipal school of Rio Grande/RS. The procedure used for data collection consisted of the application of a questionnaire that covers questions related to initial and continuing teacher training, time of teaching experience, and the subjects of Statistical studied during the graduation. Moreover contained a list of skill recommended in the National Curricular Parameters (NCPs) and in the National Curricular National Base (BNCC) in which teachers should list which are developing in their pedagogical practice. For data analysis was used the Descriptive Statistics. The results demonstrate that the skills more frequently developed indicated by the research subject's own teachers are: interpretation of information contained in images, interpretation of tables and graphs, and collection and organization of information. Considering the results of this research it is noticed that greater emphasis has been attributed to Descriptive Statistics compared to the investigative cycle of a research corroborating the findings of the State of Knowledge review.
\end{abstract}

Keywords: Statistical Education. Skills. Early Years of Elementary Education.

Resumen: Este estudio, de carácter metodológico cualitativo-cuantitativo, tiene como característica una investigación piloto de la disertación de maestría de la primera autora. El objetivo general de la investigación es la comprensión de cuales habilidades referentes a la Estadística están siendo desarrolladas en los Años Iniciales de la Enseñanza 
Fundamental. Estas están preconizadas em los documentos oficiales que orientan la Educación en este nível de enseñanza. Para tanto, se realizo uma revisión de literatura del tipo Estado del Conocimiento. Participaran de la investigación cuantitativa 12 profesores de este nivel de enseñanza que enseñaran en una escuela de la red municipal de Rio Grande/RS. El procedimiento utilizado para la adquisición de datos consistió en la aplicación de un cuestionario que abarca cuestiones relacionadas a la formación inicial y continuada de los profesores, tiempo de servicio docente, y las asignaturas de Estadística cursadas durante la graduación. Todavía contenía uma lista de habilidades preconizadas en los Parámetros Curriculares Nacionales (PCNs) y en la Base Nacional Común Curricular (BNCC), em la cual los professores deberían elegir cuales están desenvolviendo en su práctica pedagógica. Para el análisis de los datos, fue utilizada la Estadística Descriptiva. Los resultados demuestran que las habilidades desarrolladas con mayor frecuencia, indicadas por los propios professores sujetos de la investigación son: interpretación de informaciones contenidas en las imágenes, interpretación de tablas y gráficos y adquisición y organización de informaciones. Em cuanto a los resultados de esta investigación, se percebe que mayor énfasis viene siendo atribuído a la Estadística Descriptiva, em comparación com el ciclo investigativo de uma investigación, corroborando com los hallazgos de la revisión de Estado del Conocimiento.

Palabras claves: Educación Estadística. Habilidades. Años Iniciales de la Enseñanza Fundamental.

\section{INTRODUÇÃO}

A Estatística é considerada uma ciência que visa a coleta, organização, análise e interpretação de dados, subsidiando com isso, a tomada de decisão (SAMÁ, SILVA, 2013). Assim, a Estatística e o tratamento dos dados podem estar presentes em diversos contextos, como em pesquisas que medem o índice de preços ao consumidor e a taxa de desemprego, além de ensaios clínicos que determinam a eficácia de novos medicamentos (SCHEAFFER, 1990). Estas são algumas formas em que a coleta e a análise de dados desempenham papéis fundamentais nas vidas dos indivíduos. Além destes fatores, há um grande número de informações, as quais os indivíduos estão submetidos diariamente, por meio das mídias digitais e/ou impressas, tornando-se necessária a construção de conhecimentos acerca dessa ciência nas escolas. Esta demanda faz com que os cidadãos precisem desenvolver habilidades e competências específicas para compreender de forma reflexiva as informações nos âmbitos escolar, profissional ou pessoal (GAL, 2002; 2015).

A partir desta demanda social por compreender e interpretar as informações, e também de um grande movimento internacional sobre a introdução da Estatística no âmbito escolar, os documentos oficiais que norteiam a educação no país começam a abranger essa área do conhecimento. Entre eles, os Parâmetros Curriculares Nacionais (PCNs), que introduzem a Estatística desde os Anos Iniciais do Ensino Fundamental (BRASIL, 1997) e a Base Nacional Comum Curricular (BNCC), que prevê que a Estatística seja incluída desde a Educação Infantil (BRASIL, 2017).

Embora o campo da Educação Estatística esteja se constituindo como uma área de interesse de pesquisadores, segundo Borba et. al (2011), ainda é incipiente o trabalho que tem sido proposto em salas de aula. Este panorama advém, além de outros fatores, da crença de que conceitos estatísticos são de difícil compreensão por estudantes dos Anos Iniciais, tendo em vista que essa área do conhecimento era abordada, somente na Educação Superior (BORBA et al., 2011).

Os professores dos Anos Iniciais do Ensino Fundamental encontram dificuldades em incorporar a Estatística a este nível de ensino, pois possivelmente estes profissionais não tenham disposto em sua vida escolar e profissional de uma aprendizagem sistematizada sobre o assunto. A fim de apropriar-se dessa área do conhecimento, surge a necessidade de cursos de formação continuada bem como a revisão do currículo dos cursos de formação inicial (CAZORLA, 2009; GUIMARÃES et al., 2009; BORBA et al., 2011)

Borba et. al (2011) a partir das discussões que foram geradas a respeito do ensino de Estatística e Probabilidade, no Encontro Interamericano de Educação Estatística, evento da XIII Conferência Interamericana de Educação Matemática - XIII Ciaem, indicam que a Estatística nos Anos Iniciais tende a ficar restrita à Estatística Descritiva, consistindo-se apenas em uma análise descritiva de tabelas e gráficos. Logo, tem sido proposta a aprendizagem dessas representações em si mesmas e não à sua função, excluindo, dessa forma, a inferência (BORBA et al., 2011).

Posto isso, torna-se necessário pensar em estratégias e metodologias para a inserção da Estatística nos Anos Iniciais do Ensino Fundamental de forma que venha a contribuir para a autonomia e criticidade do aluno. Indo ao encontro dessa preocupação, Lopes e D'Ambrosio (2015), enfatizam que o professor precisa criar um ambiente educacional que seja propício ao desenvolvimento do 
aluno como um ser criativo, moral, responsável e que se preocupa com o bem-estar dos outros. As referidas autoras ressaltam ainda, que os professores precisam usar a criatividade para a elaboração de procedimentos que possibilitem a problematização, rompendo com metodologias de ensino que priorizam os cálculos, em detrimento da compreensão e reflexão.

Face ao exposto, o presente artigo apresenta os resultados obtidos a partir de uma pesquisa piloto, parte da dissertação de mestrado da primeira autora. A pesquisa foi realizada em uma escola municipal de Rio Grande/RS e teve por objetivo compreender quais habilidades concernentes à Estatística - preconizadas nos PCN e na BNCC - os professores dos Anos Iniciais do Ensino Fundamental estão desenvolvendo em sua prática pedagógica a fim de verificar se há um distanciamento entre a realidade escolar e o que está preconizado nos dois documentos.

Para fins de organização do texto, a seção seguinte irá abordar a Educação Estatística, a partir dos princípios apresentados nos documentos internacionais e nacionais. A seção posterior irá expor um Estado do Conhecimento das produções de programas de pós-graduação, acerca da Estatística nos Anos Iniciais do Ensino Fundamental, no que se refere a intervenções em sala de aula, visando compreender quais os aspectos referentes à Educação Estatística os pesquisadores têm interesse em investigar, e tecer possíveis aproximações com os resultados da pesquisa piloto.

\section{EDUCAÇÃO ESTATÍSTICA}

A presente seção expõe a constituição da Estatística como um campo do conhecimento a ser abordado desde o início da escolarização, versa ainda sobre alguns princípios para o desenvolvimento desta de forma a tornar o sujeito aprendente ativo na construção do seu conhecimento. Outrossim, disserta sobre as crenças, atitudes e habilidades que os sujeitos precisam desenvolver para se tornarem letrados em Estatística.

A Estatística era vista como uma parte da Matemática Aplicada (BRASIL, 2007) e, por conseguinte, ausente nos Anos Iniciais do Ensino Fundamental. Entre as décadas de 1980 e 1990, em muitos países foram introduzidas a Estatística, a Probabilidade e a Combinatória no currículo para este nível de ensino (BORBA et al., 2011).

Um projeto desenvolvido nos EUA na década de 1980, apresentado por Scheaffer (1990), o Quantitative Literacy Project (QLP), denota alguns ideais que podem nortear a prática pedagógica de professores no que tange à Educação Estatística. Dentre estes ideais estão: a análise de dados como principal ação pedagógica; as diversas maneiras de abordar um problema em Estatística; a importância da utilização de dados reais e do interesse dos alunos; a Estatística ministrada nas escolas deve ter relação com o cotidiano dos alunos; e a maior ênfase nos aspectos práticos da matemática pode mudar as atitudes sobre matemática (SCHEAFFER, 1990).

Ao encontro do exposto anteriormente, Burrill (1990) elenca uma série de princípios que constituem a filosofia do QLP. Dentre eles destacam-se: as atividades que envolvem a estatística devem ser ativas e não passivas; todos os trabalhos com as Estatísticas devem esfatizar a análise e a comunicação desta análise, em contraste com um foco em uma única resposta correta; devem instigar a reflexão dos alunos; as estatísticas devem possibilitar a interdisciplinariedade; e a tecnologia deve ser usada para facilitar a análise e interpretação.

A partir deste movimento internacional e de acordo com a demanda social, por compreender as informações que circundam os cidadãos, no Brasil, os PCN, especificamente em 1997, acrescentaram aos objetivos para o Ensino da Matemática, o Tratamento da Informação dos Anos Iniciais ao Ensino Fundamental. A preocupação dos profissionais envolvidos na elaboração destes parâmetros, era a de despertar o espírito de investigação nos alunos através da leitura e interpretação de informações contidas em imagens, coleta e organização de informações, além da produção de textos escritos a partir das interpretações destes elementos (BRASIL, 1997).

Este documento ressalta a importância de compreender que a Matemática como um componente importante na construção da cidadania, ao passo que a sociedade se utiliza, cada vez mais, de conhecimentos científicos e recursos tecnológicos. Outrossim, sugere que as práticas de Matemática no cotidiano escolar não podem instigar nos alunos um olhar para os objetos prontos e definitivos. A prática pedagógica do professor deste nível de ensino deve possibilitar a construção e a apropriação de um conhecimento pelo aluno, que se servirá dele para compreender e transformar a própria realidade (BRASIL, 1997). 
O referido documento enfatiza que a Matemática na Educação Básica deve proporcionar ao aluno um aprendizado que vai além do domínio de números, operações e fórmulas. Nesse sentido, a inserção da Estatística neste nível de ensino tem como objetivo, além de simplesmente acrescentar mais um tópico a ser estudado, dar subsídios para que os alunos, desde o início de sua escolarização, sejam letrados em Estatística (BRASIL, 1997).

Atualmente, uma nova proposta curricular está sendo elaborada, a BNCC (BRASIL, 2017). Esta apresenta, como objetivos para o ensino da Matemática na Educação Básica: o estabelecer conexões entre os eixos da Matemática e outras áreas do saber; resolver problemas criando estratégias próprias para a sua resolução, desenvolvendo a sua imaginação e criatividade; raciocinar, fazer abstrações baseadas em situações concretas, generalizar, organizar e representar; comunicar-se utilizando as diversas formas de linguagem empregadas em matemática; e utilizar a argumentação matemática apoiada em vários tipos de raciocínio. Os objetivos referentes à Educação Matemática no Ensino Fundamental são organizados neste documento em cinco eixos: Geometria, Grandezas e

Medidas, Estatística e Probabilidade, Números e Operações, e Álgebra e Funções (BRASIL, 2017).

A elaboração dos documentos mencionados, PCN (BRASIL, 1997) e BNCC (BRASIL, 2017), apresenta uma preocupação em desenvolver o espírito de investigação nos alunos. Os referidos documentos ressaltam ainda que, além das noções de representação e organização de dados no que tange ao Tratamento da Informação, a importância de desenvolver habilidades como a curiosidade, criatividade e raciocínio, sempre instigando os alunos a pensar e refletir sobre a ação que estão desenvolvendo (BRASIL, 1997; 2017).

A partir do exposto, compreende-se a importância dos sujeitos serem capazes de ler e interpretar as informações que estão presentes nos meios de comunicação (MAGALHÃES, 2015; SAMÁ; PORCIÚNCULA, 2015). Dessa forma, Gal (2002) apresenta algumas habilidades e competências para que o sujeito seja de fato alfabetizado, são elas: a) saber por que os dados são necessários e como os dados podem ser produzidos; b) familiaridade com termos e ideias básicas relacionadas à Estatística Descritiva; c) familiaridade com termos básicos e ideias relacionadas a exibições gráficas e tabulares; d) compreender as noções básicas de probabilidade; e) compreender como as conclusões ou inferências estatísticas são alcançadas.

Gal (2002) salienta que tais requisitos dizem respeito à compreensão de adultos. Entretanto, compreendemos que para que um adulto tenha tais habilidades, torna-se necessária uma imersão gradual ao longo da trajetória escolar sobre os conhecimentos estatísticos, a começar pela infância (LOPES, 2012). Sob essa perspectiva, Batanero (2001), quando concebe a Estatística como uma ciência útil para pesquisas e técnicas ligada à vida profissional e também impulsionada pelas tecnologias, percebe a criação de uma demanda para a formação básica na área. Conforme sugere a autora, devem ser incluídas recomendações gerais sobre o tema tanto nos currículos dos anos iniciais ou primário, quanto nos do secundário. Entretanto, não é essa a realidade observada na Espanha, onde, por vezes, o ensino é breve ou demasiadamente formal (BATANERO, 2001).

Segundo Gal, Ginsburg e Schau (1997), o papel das atitudes e crenças na educação estatística podem refletir na resolução de problemas. Sendo assim, os alunos precisam se sentir seguros e à vontade para explorar um campo, como a Probabilidade que pode gerar certa confusão, mesmo que temporária, pela sua incerteza. Além de acreditarem nas suas capacidades de resolução de problemas estatísticos, torna-se necessário mantê-los motivados durante o processo. Sobre esse aspecto, Scheaffer (1990) enfatiza que quando ampliamos a percepção de Matemática dos alunos, ao trabalhar com coleta e análise dados, essa ação pode motiva-los para estudar tópicos tradicionais da Matemática, construindo dessa forma, habilidades e a compreensão dos conceitos tanto estatísticos quanto matemáticos.

De maneira geral podemos compreender o termo Literacia Estatística, segundo Campos et al. (2011), como sendo a "habilidade de ler, compreender, interpretar, analisar e avaliar textos escritos" (p.23). A partir desse contexto, o termo "Literacia Estatística" nos remete às habilidades de argumentar e compreender as informações estatísticas, tais como organização de dados, construção e representação de tabelas, compreensão de conceitos e vocabulário estatístico, além da habilidade de produzir textos sobre suas compreensões.

Nesse cenário, os documentos oficiais que norteiam a educação no Brasil preveem a inserção da Estatística desde os Anos Iniciais do Ensino Fundamental (BRASIL, 1997). Recentemente, um 
novo documento que faz parte do Pacto Nacional pela Alfabetização na Idade Certa (PNAIC), publicado em 2014, aborda um capítulo sobre Educação Estatística no ciclo de Alfabetização. O PNAIC (BRASIL, 2014) tem o intuito de inserir a criança no universo da investigação através de situações de interesse próprio, em que os alunos possam realizar coletas de dados apresentandoos em gráficos e tabelas. O documento enfatiza a pesquisa como eixo estruturador da Educação Estatística neste nível de ensino, o que possibilita a articulação com outras áreas de conhecimento, tornando-a interdisciplinar, ressaltando que "aprender a fazer pesquisa favorece, não somente a formação estatística do cidadão, como, também, a formação científica” (BRASIL, 2014, p. 8).

Sendo assim,

Considera-se como fundamental na atitude investigativa a preocupação em formular questões, elaborar hipóteses, escolher amostra e instrumentos adequados para a resolução de problemas, a coleta dos dados, a classificação e representação dos mesmos para uma tomada de decisão. É nesse sentido que a pesquisa pode ser pensada como o eixo principal da formação estatística dos alunos de todos os níveis de ensino. (BRASIL, 2014, p. 5).

No que se refere à organização e planejamento de práticas pedagógicas envolvendo a Educação Estatística, Campos et al. (2011) salientam que é importante possibilitar

\begin{abstract}
aos estudantes a oportunidade de produzir os próprios dados e encontrar os resultados básicos ajuda-os a tomar as rédeas de seu próprio aprendizado. [...] É possível solicitar aos estudantes que não apenas coletem os seus dados, mas, igualmente elaborem as variáveis que irão compor seus questionários. Isso os ajuda a descobrir ou determinar métodos e técnicas por si próprios. (CAMPOS et al., 2011, p. 25-26).
\end{abstract}

Seguindo esta ótica, acredita-se que se o professor conseguir, em sua prática pedagógica, oportunizar essa autonomia, estará contribuindo para a construção da aprendizagem Estatística. Nesse contexto, segundo Lopes (2008, p. 59), "a aprendizagem da estocástica só complementará a formação dos alunos se for significativa, se considerar situações familiares a eles, que sejam contextualizadas, investigadas e analisadas".

Conforme a Estatística ganha espaço no currículo da Educação internacional com o QLP em meados de 1980 e, posteriormente, na educação brasileira com os PCN, em 1997, e atualmente com a BNCC, torna-se imprescindível refletir sobre estratégias para desenvolvê-la desde os Anos Iniciais do Ensino Fundamental. Diante desta preocupação, o PNAIC tem formato de um livro que aborda diversas formas de introduzir a Educação Estatística neste nível de ensino, tais como atividades práticas, sugestões e situações lúdicas (BRASIL, 2014). O PNAIC menciona ainda que, tanto a Estatística quanto a Probabilidade e a Combinatória, podem ser inseridas como conteúdos ainda no ciclo de alfabetização, não de forma sistematizada, mas que podem ser iniciados a partir de situações lúdicas no desenvolvimento de conceitos simples que serão gradualmente aprofundados (BRASIL, 2014).

Diante deste cenário, diversos pesquisadores de programas de pós-graduação se preocuparam em investigar a Estatística nos Anos Iniciais do Ensino Fundamental. A seção a seguir apresenta uma revisão de literatura, do tipo estado do conhecimento, com o intuito de compreender quais são os objetivos, a metodologia e os resultados destes estudos ao investigar esta temática.

\title{
3 REVISÃO DE LITERATURA SOBRE ESTATÍSTICA NOS ANOS INICIAIS DO ENSINO FUNDAMENTAL
}

A presente seção disserta sobre uma revisão de literatura, do tipo Estado do Conhecimento. Por Estado da Arte, ou Estado do Conhecimento, compreendemos pesquisas de caráter bibliográfico, que apresentam o desafio de mapear e de discutir uma certa produção acadêmica, tentando responder que aspectos e dimensões vêm sendo destacados e privilegiados e em que condições têm sido produzidas (FERREIRA, 2002). Esse tipo de pesquisa é recente no Brasil e se mostra relevante, tendo em vista que "podem conduzir à plena compreensão do estado atingido pelo conhecimento a respeito de determinado tema, sua amplitude, tendências teóricas, vertentes metodológicas" (SOARES; MACIEL, 2000, p. 9). 
Entretanto, Romanowski e Ens (2006) preconizam que as pesquisas que se caracterizam por Estado da Arte, recebem esta denominação quando abrangem toda uma área do conhecimento, ou seja, que buscam mapear e analisar as produções de diversas fontes de informação, como produções em congressos na área pesquisada, estudos sobre as publicações em periódicos, além de teses e dissertações. Dessa forma, denomina-se de Estado do Conhecimento, as pesquisas que tem uma amplitude menor, escolhendo um ou duas fontes de pesquisa, como é o caso desse capítulo da presente dissertação. Dessa forma, optamos por chamar esse capítulo de Estado do Conhecimento.

Utilizou-se como fonte de informação para a coleta de dados a Biblioteca Digital Brasileira de Teses e Dissertações (BDTD), criada em 2002 pelo Instituto Brasileiro de Informação e Tecnologia (IBICT) e a tese de Santos (2015) sobre o Estado da Arte em Educação Estatística, catalogando as produções até o ano de 2016. A metodologia empregada nesta seção tinha o intuito de catalogar e analisar os resumos de pesquisas que têm como objetivo estudar uma determinada área da Estatística: Descritiva, Inferência ou Probabilidade, valendo-se de intervenções no cotidiano escolar, até o ano de 2016. Para fins de análise optou-se pela Análise de Conteúdo de Bardin (1977).

Através desta metodologia, torna-se possível realizar um recorte do texto em unidades comparáveis de categorização para análise e de modalidade de codificação para o registro dos dados. As Categorias de Análise são abordadas por Bardin (1977) como um movimento de

[...] classificação de elementos constitutivos de um conjunto, por diferenciação e, seguidamente, por reagrupamento segundo o gênero (analogia), com os critérios previamente definidos. As categorias são rubricas ou classes, as quais reúnem um grupo de elementos (unidades de registro, no caso da análise de conteúdo) sob um título genérico, agrupamento esse efectuado em razão dos caracteres comuns destes elementos (BARDIN, 1977, p. 117).

A partir da leitura e análise dos resumos das dissertações e teses compiladas neste estudo, foram criadas três categorias, a saber: Organização de dados e representações através de gráficos e tabelas; Conteúdos e conceitos de Estatística e Probabilidade; e Processos de Avaliação na Educação Estatística. O Quadro 1 denota a categoria Organização de dados e representações através de gráficos e tabelas, em que estão destacados os títulos, os autores e ano de defesa, e os principais objetivos das pesquisas catalogadas.

Quadro 1 - Categoria de Análise: Organização de dados e representações através de gráficos e tabelas

\begin{tabular}{|c|c|c|}
\hline Título & Autor & Principais objetivos \\
\hline $\begin{array}{l}\text { Aprendendo a representar escalas } \\
\text { em gráficos: um estudo de } \\
\text { intervenção }\end{array}$ & $\begin{array}{c}\text { SILVA, M. B. E. } \\
2014\end{array}$ & $\begin{array}{l}\text { Investigar a influência de uma intervenção de ensino sobre escalas } \\
\text { representadas em gráficos de barras e linhas, com alunos do } 5^{\circ} \text { ano, a } \\
\text { partir de três tipos de atividade que exploravam o conceito de escala: } \\
\text { medidas de comprimento, reta numérica e mapas. Metodologia pré e } \\
\text { pós-teste (SILVA, 2014). }\end{array}$ \\
\hline $\begin{array}{l}\text { Classificações nos anos iniciais do } \\
\text { ensino fundamental: o papel das } \\
\text { representações }\end{array}$ & $\begin{array}{c}\text { SANTOS, L. P. } \\
2011\end{array}$ & $\begin{array}{l}\text { Investigar como alunos e professoras dos anos iniciais do Ensino } \\
\text { Fundamental classificam objetos e representam em gráficos e tabelas } \\
\text { (SANTOS, 2011). }\end{array}$ \\
\hline $\begin{array}{l}\text { Como adultos e crianças } \\
\text { compreendem a escala } \\
\text { representada em gráficos }\end{array}$ & $\begin{array}{l}\text { ALBUQUERQUE, M. R. } \\
\text { G. C. } \\
2010\end{array}$ & $\begin{array}{l}\text { Investigar como adultos e crianças dos anos iniciais de escolarização } \\
\text { compreendem a escala representada em gráficos de barras e de linha } \\
\text { (ALBUQUERQUE, 2010). }\end{array}$ \\
\hline $\begin{array}{l}\text { Introduzindo a Estatística } \\
\text { nas séries iniciais do Ensino } \\
\text { Fundamental a partir de material } \\
\text { manipulativo: uma intervenção de } \\
\text { Ensino }\end{array}$ & $\begin{array}{l}\text { CAETANO, } \\
\text { S. S. D. } \\
2004\end{array}$ & $\begin{array}{l}\text { Investigar o desenvolvimento da leitura e interpretação de gráficos } \\
\text { e o conceito de média aritmética por crianças da } 4^{a} \text { série do Ensino } \\
\text { Fundamental, por meio de uma intervenção de ensino com o uso de } \\
\text { material manipulativo (CAETANO, 2004). }\end{array}$ \\
\hline $\begin{array}{l}\text { Analisando a transformação entre } \\
\text { gráficos e tabelas por alunos do } 3^{\circ} \\
\text { e } 5^{\circ} \text { ano do ensino fundamental }\end{array}$ & $\begin{array}{c}\text { SILVA, D. B. } \\
2012\end{array}$ & $\begin{array}{l}\text { Investigar como os estudantes do } 3^{\circ} \text { e } 5^{\circ} \text { ano do Ensino Fundamental } \\
\text { realizam a transformação entre diferentes representações: do gráfico } \\
\text { para a tabela, da tabela para o gráfico, da língua natural para o gráfico } \\
\text { e da língua natural para a tabela (SILVA, 2012). }\end{array}$ \\
\hline
\end{tabular}

Ao analisarmos a Organização de dados e representações através de gráficos e tabelas, percebe-se que um número considerável de pesquisas se enquadrou nesta Categoria Temática, agrupando $55,5 \%$ das teses e dissertações nesta. Estas pesquisas versam sobre a compreensão 
de alunos e professores a respeito das representações e interpretação utilizando gráficos e tabelas, como constam nos objetivos detalhados no quadro acima.

Embora tenham o mesmo núcleo temático, as pesquisas desenvolveram trabalhos de intervenção com diferentes públicos, algumas somente com alunos (SILVA, 2014; CAETANO, 2004; SILVA, 2012) e com alunos e professores (SANTOS, 2011). Uma das pesquisas preocupouse com a compreensão dos alunos do ensino regular e da Educação de Jovens e Adultos (EJA) (ALBUQUERQUE, 2010). Caetano (2004), por sua vez, pesquisou além de gráficos e tabelas, sobre média aritmética.

A seguir, apresentaremos o delineamento metodológico das pesquisas que irá nos possibilitar compreender a metodologia de ensino empregada nas teses e dissertações dessa Categoria Temática.

Na pesquisa de Silva (2014), participaram do estudo 69 alunos de três escolas públicas. A estratégia de intervenção do autor foi realizada mediante a aplicação de um pré-teste - uma atividade prática de ensino - com 2 horas de duração, dividida em dois dias e um pós-teste com cada grupo. Estes pré e pós-teste continham oito questões que envolviam interpretação e construção de escala em gráficos. Já na pesquisa de Santos (2011), participaram 64 pessoas, destas, 48 alunos do $3^{\circ}$ ano do Ensino Fundamental e 16 professoras do mesmo nível de ensino. Na pesquisa do referido autor, foi utilizada a metodologia de entrevistas clínico-piagetianas, em que os alunos participaram de situações de classificação livre, classificação em uma tabela de dupla entrada e classificação em um gráfico cartesiano.

Em Albuquerque (2010), 152 alunos dos $3^{\circ}$ e $5^{\circ}$ anos do Ensino Fundamental e dos Módulos I, II e III da EJA participaram na pesquisa, em que foram realizados testes com o intuito de investigar quatro variáveis que estudos anteriores consideraram importantes para a compreensão da escala apresentada nos gráficos. A pesquisa de Caetano (2004) abrangeu duas classes de $4^{a}$ ano do Ensino Fundamental, em que uma delas constituiu-se de um grupo controle (GC) e a outra de um grupo experimental (GE). A pesquisa foi dividida em duas etapas: aplicação dos instrumentos diagnósticos (pré e pós-teste), tanto no GE como no GC, e aplicação da intervenção de ensino com uso de material manipulativo apenas no GE (CAETANO, 2004).

A metodologia empregada por Silva (2012) em sua pesquisa foi a aplicação de testes. Participaram desta 32 estudantes do $3^{\circ}$ e $5^{\circ}$ ano do Ensino Fundamental. Os estudantes realizaram oito atividades, sendo quatro de construção de tabela simples e quatro de construção de gráfico de barras.

As pesquisas utilizaram metodologias variadas para chegar a um objetivo similar, interpretar ou representar um conjunto de dados por meio de gráficos e tabelas. Dentre elas, se destacou a utilização de testes únicos ou ainda a realização de um pré-teste seguido de uma intervenção e, posteriormente, aplicação outro teste para medir o desempenho anterior e posterior às intervenções.

No que tange aos resultados das pesquisas dessa Categoria Temática, a partir da análise dos resumos destacaremos somente os pontos principais, Silva (2014) descobriu com o pré-teste que os conhecimentos dos alunos eram debilitados, porém, com apenas duas intervenções de $1 \mathrm{~h}$ cada, os alunos melhoraram consideravelmente seu desempenho no pós-teste. Na pesquisa de Santos (2011), foi observado que a maioria dos participantes - tanto alunos quanto professores -, apresentou dificuldades em classificar, independentemente da situação proposta. Albuquerque (2010) percebeu em sua dissertação, que os alunos investigados não apresentaram um bom desempenho nessas questões. Na maioria das atividades, as crianças, tiveram desempenho melhor do que os adultos.

Os resultados da pesquisa de Caetano (2004) apontaram para as dificuldades dos alunos na leitura e interpretação de gráficos em situações específicas. Quanto à média aritmética, os resultados mostraram um crescimento de quase $50 \%$ no desempenho dos alunos do GE no pósteste. A dissertação de Silva (2012) revelou que o desempenho dos estudantes em atividades que visam à transformação entre tabelas e gráficos e vice-versa, não mostrou diferenças significativas. A autora enfatiza que os estudantes obtiveram melhor desempenho em atividades de construção de gráficos.

Podemos inferir que, os resultados são mais satisfatórios quando são propostas atividades que instiguem os alunos a pensar e refletir sobre o que estava exposto em uma tabela ou gráfico, para que pudessem representá-los de outras formas. Nessa perspectiva, torna-se necessário que o trabalho com as representações gráficas seja desenvolvido com maior ênfase nos anos iniciais 
do Ensino Fundamental, tornando o aluno ativo em seu processo ensino/aprendizagem. Desse modo, compreendemos que uma estratégia de aprendizagem seria possibilitar ao aluno que este participasse de todo o processo, desde a escolha de um tema até a coleta e organização dos dados, pois assim ele irá atribuir significado àquilo que está sendo desenvolvido, como preconizam os documentos que norteiam a educação em nosso país (BRASIL, 1997; 2014).

Abaixo apresentamos o Quadro 2, que aborda a Categoria Temática Conteúdos e conceitos de Estatística e Probabilidade, que reuniu três pesquisas que apresentam como objetivos investigar as compreensões tanto de alunos como de professores acerca dos conteúdos de Estatística e/ou Probabilidade.

Quadro 2 - Categoria de Análise: Conteúdos e conceitos de Estatística e Probabilidade

\begin{tabular}{|l|c|l|}
\hline \multicolumn{1}{|c|}{ Título } & Autor & \multicolumn{1}{c|}{ Principais objetivos } \\
\hline $\begin{array}{l}\text { Para variar: compreensões } \\
\text { de estudantes dos anos } \\
\text { iniciais diante de aspectos da } \\
\text { variabilidade }\end{array}$ & $\begin{array}{c}\text { CAVALCANTI, } \\
\text { E. M. S. }\end{array}$ & $\begin{array}{l}\text { Investigar as compreensões apresentadas por estudantes do } \\
2^{\circ} \text { e } 5^{\circ} \text { ano a respeito do conceito de variabilidade estatística } \\
\text { (CAVALCANTI, 2011). }\end{array}$ \\
\hline $\begin{array}{l}\text { Fazendo média: compreensões } \\
\text { de alunos e professores dos anos } \\
\text { iniciais do ensino fundamental }\end{array}$ & 2011 & $\begin{array}{l}\text { Investigar como o conceito de média aritmética é compreendido } \\
\text { por alunos e professores dos anos iniciais do Ensino Fundamental, } \\
\text { considerando diferentes invariantes, significados e representações } \\
\text { (MELO, 2010). }\end{array}$ \\
\hline $\begin{array}{l}\text { Probabilidade: significados } \\
\text { atribuídos por alunos do ciclo II do } \\
\text { ensino fundamental }\end{array}$ & STELMASTCHUCK, A. H. C. M. & $\begin{array}{l}\text { Realizar um estudo sobre as respostas dos estudantes do Ciclo II } \\
\text { de escolas da Rede Municipal de Ensino de Curitiba em atividades } \\
\text { que contemplam o conteúdo de Probabilidade (STELMASTCHUCK, } \\
\text { 2009). }\end{array}$ \\
\hline
\end{tabular}

Fonte: Registros pessoais de coleta de dados (2017)

Nesta categoria foi possível agrupar três pesquisas que desenvolveram intervenções visando investigar a compreensão dos alunos dos Anos Iniciais do Ensino Fundamental, sobre os conceitos de variabilidade estatística e de média aritmética, bem como sobre o conteúdo de Probabilidade (CAVALCANTI, 2011; MELO, 2010; STELMASTCHUCK, 2009).

A pesquisa de Cavalcanti (2011) desenvolveu cinco atividades abordando diferentes aspectos da variabilidade. Os participantes da pesquisa foram alunos do $2^{\circ}$ e $5^{\circ}$ anos, com os quais foram realizadas entrevistas clínico-piagetianas, visto que o intuito da pesquisa era investigar as justificativas dadas pelos estudantes frente às questões propostas. Nesta categoria, engloba-se a pesquisa de Melo (2010), na qual participaram 210 sujeitos dos $3^{\circ}$ e $5^{\circ}$ anos, destes 31 professores. $\mathrm{Na}$ intervenção foi solicitado que cada sujeito respondesse individualmente a um teste com sete questões a partir da Análise da Estrutura de Similaridade (SSA).

No que tange aos conteúdos de probabilidade, a pesquisa de Stelmastchuck (2009) questiona os alunos sobre o uso da probabilidade em problemas escolares. Os dados coletados foram analisados à luz do Modelo Teórico dos Campos Semânticos, proposto por Romulo Campos Lins. Este modelo estuda os modos de produção de significados para textos. A partir dos dados coletados e com base neste referencial, propõe-se uma categorização para os significados atribuídos pelos estudantes ao conteúdo das atividades apresentadas.

Partindo para uma busca exploratória na dissertação de Cavalcanti (2011), percebemos que sua metodologia ocorreu através da aplicação individual de um conjunto de cinco questões aos alunos, garantindo, dessa forma, que a pesquisadora pudesse acompanhar o processo de aprendizagem através das falas dos alunos, capturadas enquanto justificavam a sua resposta em cada questão. O que diferencia esta pesquisa das outras é o grau de profundidade empregado nas respostas dos alunos.

No que tange aos resultados das pesquisas dessa Categoria Temática, Cavalcanti (2011) constatou que os alunos do $5^{\circ}$ ano apresentaram um desempenho significativamente maior do que os estudantes do $2^{\circ}$ ano, em pelo menos metade das questões, entretanto, no final da análise, percebese que os estudantes do $2^{\circ}$ ano também conseguem compreender aspectos da variabilidade. Sendo assim, tal pesquisa pode auxiliar professores a desmistificar a crença de que estudantes dos anos iniciais são incapazes de compreender tais conceitos, como referiram Borba et al. (2011), auxiliando 
desse modo, na disseminação de que os conhecimentos que versam sobre a Estatística nos anos inicias podem ser desenvolvidos e compreendidos por alunos neste nível de ensino.

Os resultados da pesquisa de Melo (2010) apontam um desempenho muito fraco dos alunos e não foram observadas diferenças significativas entre os níveis de escolaridade. Os professores apresentaram um desempenho significativamente superior ao dos alunos, entretanto, ainda um pouco rudimentar.

Em uma busca na dissertação de Stelmastchuck (2009), percebe-se que os dados foram coletados a partir de três atividades que versavam sobre a Estatística. A autora apresenta como resultados, uma categorização para os significados atribuídos pelos estudantes ao conteúdo das atividades que Ihes foram apresentadas. Esta categorização possibilitou a compreensão de como o conceito de Probabilidade é assimilado pelos estudantes.

A seguir destacamos a Categoria Temática Processos de Avaliação na Educação Estatística.

Quadro 3 - Categoria de Análise: Processos de Avaliação na Educação Estatística

\begin{tabular}{|c|c|c|}
\hline Título & Autor & Principais objetivos \\
\hline $\begin{array}{l}\text { A avaliação do movimento de ensinar e } \\
\text { aprender matemática nos anos iniciais } \\
\text { do ensino fundamental }\end{array}$ & $\begin{array}{l}\text { SILVA, D. } \\
\text { S. G. } \\
2014\end{array}$ & $\begin{array}{l}\text { Analisar como o processo de avaliação contribui para a organização do ensino } \\
\text { de matemática nos anos iniciais do Ensino Fundamental, a partir de uma } \\
\text { atividade de ensino sobre estatística em uma turma de } 5^{\circ} \text { ano (SILVA, 2014). }\end{array}$ \\
\hline
\end{tabular}

Fonte: Registros pessoais de coleta de dados (2017)

A presente categoria apresenta uma publicação referente à pesquisa de Silva (2014), que tem como objetivo analisar o processo de avaliação e sua contribuição à organização do ensino de Estatística nos anos iniciais do Ensino Fundamental. A pesquisa foi realizada no âmbito do Clube de Matemática (CluMat), a partir de uma atividade de ensino sobre estatística com uma turma do $5^{\circ}$ ano, na qual a pesquisadora atua como professora. Para a análise dos dados, a autora utiliza como referencial a Teoria Histórico-Cultural (THC) de Vygotsky e a Teoria da Atividade de Leontiev.

Diante dos resultados da pesquisa, a autora referida acima, percebe que o processo de avaliação vai além de realizar testes para saber se o aluno está ou não aprendendo. Nesse sentido, a avaliação precisa ser um processo contínuo, garantindo ao professor refletir sobre as ações desenvolvidas durante todo o processo de ensino/aprendizagem. (SILVA, 2014)

Em linhas gerais, a metodologia empregada por grande parte das pesquisas foi a realização de testes para medir o conhecimento tanto de alunos quanto de professores. Tal fato, nos faz refletir sobre as estratégias de avaliação que estão sendo utilizadas em sala de aula, tanto por professores quanto pelos pesquisadores, e que podem evidenciar a avaliação dos alunos nos anos iniciais do Ensino Fundamental por meio de testes, e provas.

A próxima sessão visa descrever os aspectos metodológicos dessa pesquisa piloto, seguida de uma breve discussão e algumas considerações.

\section{CAMINHOS METODOLÓGICOS}

Entende-se por metodologia o caminho do pensamento e a prática a ser exercida na abordagem da realidade, inclui concepções teóricas, além de um conjunto de técnicas que possibilitam apreender aspectos da realidade que se pretende investigar (MINAYO, 1994).

A presente pesquisa, apresenta além de um Estado Conhecimento, apresentado na seção anterior, um estudo quantitativo, este tipo de pesquisa, como denota Fonseca (2002):

\footnotetext{
Diferentemente da pesquisa qualitativa, os resultados da pesquisa quantitativa podem ser quantificados. [...] A pesquisa quantitativa se centra na objetividade. Influenciada pelo positivismo, considera que a realidade só pode ser compreendida com base na análise de dados brutos, recolhidos com o auxílio de instrumentos padronizados e neutros. A pesquisa quantitativa recorre à linguagem matemática para descrever as causas de um fenômeno, as relações entre variáveis, etc. (FONSECA, 2002, p. 20).
}

O autor salienta que a utilização conjunta da pesquisa qualitativa e quantitativa permite recolher mais informações do que se poderia conseguir isoladamente (FONSECA, 2002). Nesse contexto, é importante esclarecer que esta é uma pesquisa piloto de uma dissertação de mestrado, que tem como metodologia a abordagem quantitativa-qualitativa. 
Quanto aos seus objetivos, esta pesquisa piloto pode ser considerada como descritiva, que de acordo com Gil (2002), pretende descrever as características de uma população ou fenômeno e/ou estabelecer relações entre variáveis através de técnicas padronizadas de coleta de dados, como o uso do questionário.

Dessa forma, quanto aos procedimentos e instrumentos utilizados, o estudo visa coletar informações por meio de um questionário destinado aos professores que lecionam nos Anos Iniciais do Ensino Fundamental de uma escola municipal de Rio Grande/RS, totalizando 12 professoras. Este contém, primeiramente, perguntas abertas que abordam questões referentes à caracterização dos sujeitos: a formação, se cursaram disciplinas de Estatística durante a graduação, tempo de atuação no magistério e se ministram disciplinas de Estatística em sua prática pedagógica.

A segunda parte do questionário consiste em uma lista de habilidades, preconizadas nos documentos oficiais que norteiam a educação no país, os PCN's e a atual BNCC, para o Tratamento da Informação ou Estatística. Nesta, os professores marcaram com um " $x$ " as habilidades que desenvolvem em sua prática pedagógica com os alunos.

A partir do exposto até aqui, compreendemos que quanto aos seus procedimentos, esta pesquisa se caracteriza por um levantamento, com o intuito de recolher informações acerca de um universo especifico, ou seja, sobre um determinado comportamento que se deseja conhecer (GIL, 2002).

Nesse cenário, o objetivo desse estudo é compreender quais habilidades referentes à Estatística estão sendo desenvolvidas nos Anos Iniciais do Ensino Fundamental. Obtém-se como hipótese inicial que, de acordo com alguns autores, como Borba et al. (2011), a Estatística nesse nível de ensino tende a ficar restrita à Estatística descritiva.

No que tange à análise dos dados coletados através do questionário, nos valemos da Estatística Descritiva, que tem por objetivo tanto a coleta, organização e apresentação dos dados por meio de gráficos e tabelas (SAMÁ, SILVA, 2013). A pesquisa piloto outrossim contempla uma análise estatística, de algumas variáveis que compõe o questionário, como: cursar uma disciplina de Estatística durante a graduação e desenvolver objetivos previstos nos documentos oficiais para o ensino da Estatística nos Anos Iniciais do Ensino Fundamental;

Para tanto, valemo-nos de testes não paramétricos, que segundo Dancey e Reidy (2006) são recomendados quando as pesquisas têm amostras pequenas, ou ainda quando os dados não foram retirados de uma amostra com distribuição normal. Dessa forma, opta-se neste estudo pelo

Coeficiente de Correção de $\rho \rho$ Spearman, tendo em vista o tamanho da população investigada, totalizando 12 profissionais.

\section{DISCUSSÃO DOS RESULTADOS}

Esta seção destina-se à análise dos resultados da pesquisa piloto realizada em uma escola Municipal, abrangendo a população de 12 professoras que lecionam nos Anos Iniciais do Ensino Fundamental.

No que tange aos anos de experiência na docência das professoras investigadas, verificou-se que a média dos é de 23,41 anos, entretanto o conjunto dos dados tem uma amplitude total de 37 anos. Constatamos que $83,33 \%$ das professoras alegou ter cursado disciplinas de Estatística durante a graduação, entretanto, $50 \%$ dessas não se recordam dos conteúdos ministrados nas disciplinas de Estatística. As demais, relatam que os conteúdos versavam sobre Estatística Básica, ou ainda aplicada à Educação, entretanto, as atividades abordavam índices e pesquisas educacionais, sem um viés didático que as preparassem para o ensino da Estatística nos Anos Iniciais do Ensino Fundamental.

A formação dos professores, de acordo com alguns autores, pode influenciar nas suas práticas pedagógicas, concernente aos conteúdos de Estatística (CAZORLA, 2009; GUIMARÃES et al., 2009; BORBA et al., 2011).

Dentre as professoras, que alegaram ter cursado pelo menos uma disciplina de Estatística durante a graduação, apenas uma delas (10\%) relata não abordar esse conteúdo em sua prática pedagógica, justificando que esse conteúdo não faz parte do currículo escolar. Essa situação denota o quanto a prática de alguns professores pode se tornar isolada dos documentos que norteiam a educação, tanto a nível nacional como municipal. 
Por outro lado, as professoras que elencaram não ter cursado nenhuma disciplina referente à Estatística durante a graduação $(16,76 \%)$, alegaram desenvolver conteúdos estatísticos em sua prática pedagógica, por meio de gráficos e tabelas.

Nesse contexto, realizou-se um teste para medir a relação, entre as variáveis: cursar uma disciplina de Estatística durante a graduação e desenvolver objetivos previstos nos documentos oficiais para o ensino da Estatística nos Anos Iniciais do Ensino Fundamental, utilizando-se coeficiente de $\rho \rho$ Spearman. Os resultados deste teste encontram-se expostos no Quadro 4.

Quadro 4 - Correlação entre as variáveis, disciplinas de Estatística durante a graduação e a prática pedagógica

\begin{tabular}{|c|c|c|c|c|}
\hline \multicolumn{3}{|c|}{ Correlação } & Disciplina & Prática \\
\hline \multirow{6}{*}{ Spearman's rho } & \multirow{3}{*}{ Disciplina } & Correlation Coefficient & 1,000 &,- 135 \\
\hline & & Sig. (2-tailed) & & ,676 \\
\hline & & $\mathrm{N}$ & 12 & 12 \\
\hline & \multirow{3}{*}{ Prática } & Correlation Coefficient &,- 135 & 1,000 \\
\hline & & Sig. (2-tailed) & ,676 & \\
\hline & & $\mathrm{N}$ & 12 & 12 \\
\hline
\end{tabular}

Diante do quadro $x$, compreende-se que há uma correlação não significativa entre as variáveis $(n=12, \rho \rho=-0,135)$. Assim sendo, é possível inferir que a variável, ter cursado Estatística durante a graduação, não tem influência na prática pedagógica dos profissionais fazem parte dessa pesquisa, no que tange aos objetivos previstos nos documentos PCN (BRASIL, 1997) e BNCC (BRASIL, 2017) e vice-versa. Tal resultado corrobora ao observado nas respostas dos questionários, pois a maioria dos professores desenvolvem conteúdos estatísticos em sua práxis, tendo cursado ou não disciplinas referentes a esse conteúdo.

Outrossim, valemo-nos do coeficiente de $\rho \rho$ Spearman, para verificar se há correlação entre o tempo de experiência na docência e número de objetivos preconizados nos documentos oficiais, que os professores alegaram desenvolver em sua prática. A seguir o quadro 5 apresenta esta correlação.

Quadro 5 - Correlação entre as variáveis, tempo de experiência docente e número de objetivos contemplados na prática pedagógica

\begin{tabular}{|l|l|l|r|r|}
\hline \multicolumn{2}{|c|}{ Correlação } & Experiência & objetivos \\
\hline \multirow{4}{*}{ Spearman's rho } & \multirow{3}{*}{ Experiência } & Correlation Coefficient & 1,000 &,- 452 \\
\cline { 3 - 5 } & & Sig. (2-tailed) &. &, 140 \\
\cline { 2 - 5 } & $\mathrm{N}$ & 12 & 12 \\
\cline { 2 - 5 } & \multirow{3}{*}{ objetivos } & Correlation Coefficient &,- 452 & 1,000 \\
\cline { 3 - 5 } & & Sig. (2-tailed) &, 140 & 12 \\
\cline { 3 - 5 } & $\mathrm{N}$ & 12 & 12 \\
\hline
\end{tabular}

Fonte: Registros pessoais de coleta de dados (2017)

A partir do exposto no Quadro 5 identifica-se uma correlação negativa ( $n=12, \rho \rho=-, 495)$. Nesse sentido, quanto maior o tempo de experiência do professor, menos conteúdos referentes à Estatística são abordados em sua prática. Pode-se inferir que está realidade é atribuída, além de outros fatores, ao tempo de formação das professoras investigadas nesse estudo, que é em média 23 anos, ao passo que a Estatística e o Tratamento da informação foram introduzidos em 1997 com os Parâmetros Curriculares Nacionais, ou seja, posteriormente à formação inicial dessas profissionais.

Em seguida, são apresentadas as habilidades previstas nos documentos oficiais que norteiam a educação brasileira, que os professores conseguem desenvolver em suas práticas pedagógicas, como apresenta o Gráfico 1. 
Gráfico 1: Frequência das habilidades previstas nos documentos oficiais

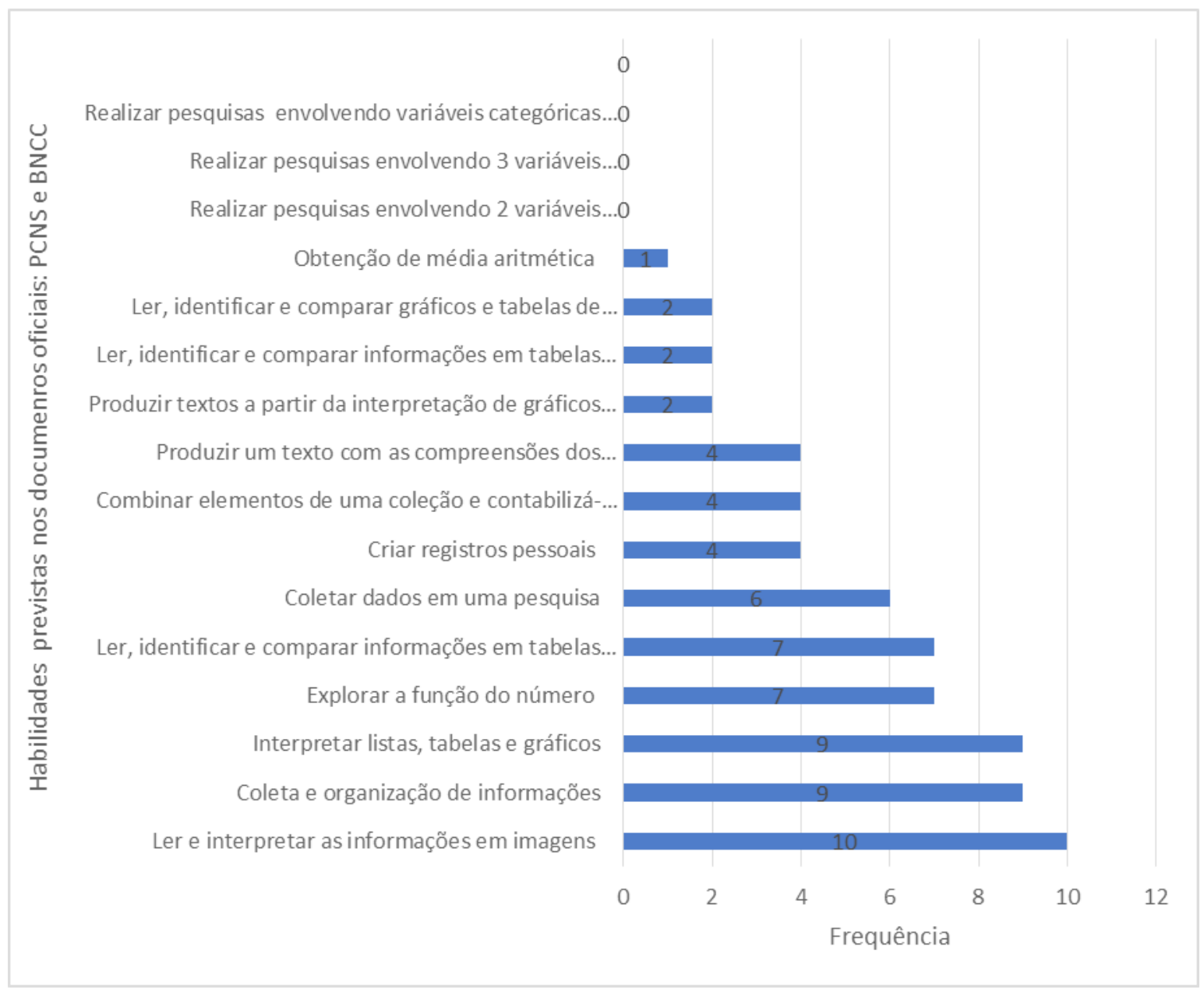

Fonte: Dados da pesquisa

De acordo com o Gráfico 1, percebe-se que dentre as habilidades referentes ao ensino da Estatística, que são desenvolvidas na prática pedagógica das professoras investigadas, se destacaram: ler e interpretar as informações em imagens; coleta e organização de informações; interpretar listas, tabelas e gráficos, tais habilidades englobam $41 \%$ dos conteúdos.

Nesse contexto, a representação gráfica das séries estatísticas tem por finalidade representar os resultados obtidos, permitindo que se chegue a conclusões sobre a evolução do fenômeno ou sobre como se relacionam os valores da série. A escolha do gráfico mais apropriado ficará a critério do analista, aluno, sujeito que está analisando o material. Contudo, os elementos simplicidade, clareza e veracidade devem ser considerados, quando da elaboração de um gráfico (CORREA, 2003).

De acordo com Correa (2003), o trabalho com interpretação de gráficos pode desenvolver aspectos como,

\begin{abstract}
Declarar qual o fenômeno ou fenômenos representados, a região considerada, o período de tempo, a fonte dos dados, etc; Examinar o tipo de gráfico escolhido, verificar se é o mais adequado, criticar a sua execução, no conjunto e nos detalhes; Analisar cada fenômeno separadamente, fazendo notar os pontos mais em evidência, o máximo e o mínimo, assim como as mudanças mais bruscas; Investigar se há uma "tendência geral" crescente ou decrescente ou, então, se o fato exposto é estacionário; Procurar descobrir a existência de possíveis ciclos periódicos, qual o período aproximado, etc. (CORREA, 2003, p. 23).
\end{abstract}

Embora compreenda-se a importância de desenvolver com os alunos habilidades referentes a leitura e análise gráfica e tabular, existe outrossim, as habilidades que estão envolvidas na coleta, organização dos dados, análise, e construção de pequenos textos para comunicar as conclusões da pesquisa, que são igualmente importantes à formação dos alunos, como preconizam os documentos 
oficiais PCN's e BNCC. Contudo, nessa pesquisa percebe-se que o ensino da Estatística nos Anos Iniciais tende a ficar restrito a análise descritiva de tabelas e gráficos, atestando a hipótese inicial dessa pesquisa, corroborado com Borba et al. (2011).

A Educação Estatísta abrange além da construção e compreensão de gráficos e tabelas, o ciclo investigativo de uma pesquisa, ao desenvolver e possibilitar aos alunos atividades de pesquisa. Abrangendo desde a escolha do tema, utilizando de dados reais e de interesse dos alunos, levantamentos de hipóteses sobre o tema investigado, técnicas para coletar e organizar os dados. Uma pesquisa compreende ainda, a escolha de materiais para comuniar os resultados e conclusões, para tanto pode-se utilizar as tecnologias, por exemplo. Se tais atividades forem trabalhadas de maneira contextualizada, podem tornar os alunos, sujeitos ativos no seu processo de ensino e aprendizagem (SCHEAFFER, 1990; BURRILL, 1990).

Nesse contexto, as habilidades que versam sobre a realização de pesquisas, primeiramente tendo como universo a turma, em seguida com 30 elementos ou mais, utilizando variáveis categóricas ou númericas, englobou somente $6 \%$ das práticas dos professores nos Anos Iniciais do Ensino Fundamental.

Os dados acima apresentam que a Estatística se faz presente na sala de aula nos Anos Iniciais do Ensino Fundamental, principalmente por meio de gráficos e tabelas, e secundariamente através de pesquisas. Esse panorama contempla alguns dos aspectos precozinados nos domcumentos oficiais que norteiam a educação básica em nosso país, os PCN's, e BNCC. Entretanto, percebeu-se que menor ênfase tem se atribuído às pesquisas, tendo primeiramente como público alvo, a própria turma e posteriormente outras populações.

O interesse nesse estudo em acrescentar no questionário as habilidades da BNCC, que ainda está em fase aprovação, consiste na preocupação de verificar se os objetivos e habilidades preconizados nos documentos oficiais que norteiam a educação no Brasil estão distanciados do cotidiano escolar. Os dados discutidos anteriormente corroboram essa preocupação, pois de fato, na escola investigada, existe um grande distanciamento entre os documentos oficiais e a prática do professor, no que tange principalmente ao ciclo investigativo de uma pesquisa.

A partir dessa situação torna-se interessante a reflexão sobre a atual BNCC acrescentar tantos objetivos referentes a educação, se os dados mostram que os professores ainda não estão contemplando o que foi postulado em 1997 com os PCN's. Essa realidade apresenta uma lacuna entre o que está previsto nos documentos oficiais da educação brasileira e o que realmente é realizado no cotidiano escolar, acredita-se que mais do que acrescentar uma série de objetivos a serem desenvolvidos pelos professores, é importante o investimento em formação continuada, para que os mesmos tenham subsídios para refletir e colocar em prática o que esses documentos preveem.

Corroborando a discussão anteior, algumas professoras demonstraram ainda não ter clareza das teorias que subjazem a sua prática pedagógica, afirmando em uma questão do questionário que não desenvolvem habilidades referentes à Estatística com seus alunos e posteriormente, os mesmos profissionais marcaram diversas habilidades que desenvolvem na sua prática pedagógica.

A partir dessa análise concebe-se que embora a Estatística esteja presente nos Anos Iniciais, por meio de gráficos e tabelas, o ciclo investigativo de uma pesquisa, ainda é pouco realizado. Nesse cenário é importante refletirmos sobre possíveis formas de ampliar essa visão da Estatística nesse nível de ensino, investindo em cursos de formação continuada, maior valorização do profisional da educação, entre outros elementos que interferem na prática pedagógica dos professores.

\section{ALGUMAS CONSIDERAÇÕES}

AEstatística foi inserida no currículo escolar, a partir de um movimento internacional atravessado a uma demanda da sociedade brasileira, em compreender as informações veiculadas nas mídias televisivas e impressas, primeiramente com os PCN's, e atualmente com a BNCC.

Entretanto, como destacam alguns autores, os profissionais da educação podem enfrentar algumas dificuldades em introduzir a Estatística nos Anos Iniciais do Ensino Fundamental, pela crença de que as crianças dessa faixa etária não têm maturidade para compreender os conteúdos estatísticos. Outrossim, pela formação dos professores que muitas vezes não compreende a didática para o ensino da Estatística para esse nível de escolarização. 
O objetivo geral dessa pesquisa era compreender quais habilidades referentes ao ensino e aprendizagem da Estatística os professores dos Anos Iniciais do Ensino Fundamental estão desenvolvendo em sua prática pedagógica. Tendo como pressuposto inicial que de acordo com alguns autores a Estatística nesse nível de ensino tende a ficar restrita à Estatística descritiva.

Diante dos resultados com a pesquisa quantitativa, realizada em uma escola municipal de Rio Grande, percebemos que embora a maioria das professoras tenham cursado pelo menos uma disciplina de Estatística durante a sua graduação, muitas delas relatam que não recordam dos conteúdos ministrados nessas disciplinas. No entanto, outras professoras enfatizam que estas as disciplinas não tinham um caráter didático, portanto não as prepararam para o ensino da Estatística.

Dessa forma, a suposição inicial foi confirmada, pois, as habilidades estatísticas que são abordadas com maior frequência nos Anos Iniciais de uma escola municipal de Rio Grande, são interpretação de informações contidas em imagens, interpretação de tabelas e gráficos e coleta e organização de informações. Compreende-se que menor ênfase tem sido atribuída ao ciclo investigativo de uma pesquisa nesse nível de ensino.

Os resultados dessa pesquisa piloto denotam que a Estatística nos Anos Inicias do Ensino Fundamental, mesmo após 20 anos da publicação dos PCN's, ainda não comtempla todos os objetivos preconizados nesse documento. Enfatizando o distanciamento que tanto os PCN's quando a atual BNCC tem em relação a prática pedagógica dos professores desse nível de ensino.

Nesse contexto, torna-se necessário refletir sobre possíveis formas de inserir a Estatística desde os Anos Iniciais do Ensino Fundamental, como o investimento na formação continuada dos professores, para que possamos além de abranger os objetivos previstos PCN's contemplar as habilidades presentes na BNCC, que está em fase de aprovação, com o intuito de garantir uma formação de qualidade aos estudantes, desenvolvendo habilidades referentes a sua criticidade, autonomia e reflexão perante a sua realidade social. 


\section{REFERÊNCIAS}

ALBUQUERQUE, M. R. G. C. Como adultos e crianças compreendem a escala representada em gráficos. Recife, PE: 2010. Originalmente apresentada como dissertação de mestrado, Universidade Federal de Pernambuco, 2010.

BARDIN, L. Análise de conteúdo. Lisboa: Edições 70, 1977.

BATANERO, C. Didáctica de la Estadística. Departamento de Didáctica de la Matemática, Universidad de Granada, 2001. Disponível em: <http://www. pucrs.br/famat/viali/graduacao/matematica/material/ referencias/didacticaestadistica.pdf>. Acesso em: 05 nov. 2017.

BORBA, R. et al. Educação Estatística no ensino básico: currículo, pesquisa e prática em sala de aula. Revista de Educação Matemática e Tecnológica Ibero-americana, v. 2, n.2, 2011.

BRASIL. Ministério da Educação. Parâmetros Curriculares Nacionais (PCN): matemática. Brasília, DF, 1997.

. Ministério da Educação. Estatística aplicada à educação. Brasília, DF, 2007.

Ministério da Educação. Pacto Nacional pela Alfabetização na Idade Certa (PNAIC): Educação Estatística. Brasília, DF, 2014.

Ministério da Educação. Base Nacional Comum Curricular (BNCC): Educação é a Base. Brasília, DF, 2017.

BURRILL, G. Quantitative Literacy - Implementation Through Teacher Inservice. In:

INTERNATIONAL CONFERENCE ON TEACHING STATISTICS, 3, 1990, New Zealand. Anais... Dunedin: New Zealand, 1990. p. 50-55.

CAETANO, S. S. D. Introduzindo a Estatística nas séries iniciais do Ensino Fundamental a partir de material manipulativo: uma intervenção de Ensino. São Paulo, SP: 2004. Originalmente apresentada como dissertação de mestrado, Pontifícia Universidade Católica de São Paulo, 2004.

CAMPOS, C. R. et al. Educação Estatística: teoria e prática em ambientes de modelagem matemática. Belo Horizonte: Autêntica Editora, 2011.

CAVALCANTI, E. M. S. Para variar: compreensões de estudantes dos anos iniciais diante de aspectos da variabilidade. Recife, PE: 2011. Originalmente apresentada como dissertação de mestrado, Universidade Federal de Pernambuco, 2011.
CAZORLA, I. M. O ensino da Estatística no Brasil. Sociedade Brasileira de Educação Matemática, 2009. Disponível em <http://www.sbem.com.br/ gt_12/arquivos/cazorla.htm> Acesso em: 16 ago. 2017.

CORREA, S. M. B. Probabilidade e Estatística. 2. ed. Belo Horizonte: PUC Minas Virtual, 2003. Disponível em:<http://estpoli.pbworks.com/f/livro_probabilidade_estatistica_2a_ed.pdf>. Acesso em 1 nov. 2017.

DANCEY, C. P; REIDY, J. Estatística sem matemática para psicologia. Porto Alegre: Artmed, 2006.

FERREIRA, Norma S. A. As Pesquisas Denominadas "Estado Da Arte" Educação \& Sociedade, ano XXIII, no 79, Agosto/2002. Disponível em: <file:///C:/ Users/thayv/Downloads/Estado\%20da\%20arte\%20 Ferreira\%20-2-\%20-1.pdf>. Acesso em 1 nov. 2017.

FONSECA, J. J. S. da. Metodologia da Pesquisa Científica. UECE - Universidade Estadual do Ceará, 2002. Disponível em: <http://leg.ufpi.br/subsiteFiles/ lapnex/arquivos/files/Apostila_-_METODOLOGIA DA_PESQUISA(1).pdf >. Acesso: em 20 out. $201 \overline{7}$.

GAL, I. Adults Statistical Literacy: meanings, components, responsibilities. International Statistical Review, v. 70, n. 1, p. 1-25, 2002.

, I. Prefácio. In: SAMÁ, S.; SILVA, M. P. M. da. (Org.). Educação Estatística: ações e estratégias pedagógicas no Ensino Básico e Superior. Curitiba: CRV, 2015, p. 17-25.

GAL, I.; GINSBURG, L.; SCHAU, C. Monitoring attitudes and beliefs in statistics education. In: GAL, I.; GARFIELD, J. B. (Eds.). The assessment challenge in statistics education. Voorburg, Netherlands: IOS Press, p. 37-51, 1997. Disponível em: <https://www. stat.auckland.ac.nz/ iase/publications/assessbk/ chapter04.pdf>. Acesso: em 20 out. 2017.

GIL, A. C. Como elaborar projetos de Pesquisa. São Paulo: Atlas, 2002.

GUIMARÃES, G. et al. Educação estatística na educação infantil e nos anos iniciais. Zetetiké - Cempem - FE - Unicamp, Campinas, v. 17, n. 2, p. 1128, jul/dez. 2009.

LOPES, C. E. O ensino da Estatística e da Probabilidade na Educação Básica e a formação dos professores. Cad. Cedes, Campinas, v. 28, n. 74, p. 57-73, jan./abr. 2008. 
C. E. A educação estocástica na infância. Revista Eletrônica de Educação, v. 6, n. 1, p. 160174, mai. 2012.

LOPES, C.; D’AMBRÓSIO, B. Perspectivas para a Educação Estatística de futuros educadores matemáticos de infância. In: SAMÁ, S.; SILVA, M. P. M. da. (Org.). Educação Estatística: ações e estratégias pedagógicas no Ensino Básico e Superior. Curitiba: CRV, 2015, p. 17-25.

MAGAHÃES, M. Desafios do ensino da Estatística na licenciatura em Matemática. In: : SAMÁ, S.; SILVA, M. P. M. da. (Org.). Educação Estatística: ações e estratégias pedagógicas no Ensino Básico e Superior. Curitiba: CRV, 2015, p. 17-25.

MELO, M. C. M. Fazendo média: compreensões de alunos e professores dos anos iniciais do Ensino Fundamental. Recife, PE: 2010. Originalmente apresentada como dissertação de mestrado, Universidade Federal de Pernambuco, 2010.

MINAYO, M. C. Ciência, técnica e arte: o desafio da pesquisa social. In: DESLANDES, S. F.; CRUZ NETO, O.; GOMES, R.; MINAYO, M. C. (Org). Pesquisa social: teoria, método e criatividade. Petrópolis: Vozes, 1994.

ROMANOWSKI, J. P.; ENS, R. T. As pesquisas denominadas do tipo "estado da arte" em educação. Diálogo Educ., Curitiba, v. 6, n. 19, p. 37-50, set/dez de 2006.

SAMÁ, S.; SILVA, C. S. Estatística V. I. Porto Alegre: Editora da FURG, 2013.

SAMÁ, S.; PORCUÚNCULA, M. (orgs) Educação Estatística: ações e estratégias pedagógicas no Ensino Básico e Superior. Org.. p. 17-25. Curitiba, PR: CRV, 2015.
SANTOS, P. L. da. Classificações nos anos iniciais do ensino fundamental: o papel das representações. Recife, PE: 2011. Originalmente apresentada como dissertação de mestrado, Universidade Federal de Pernambuco, 2011.

SANTOS, R. M. dos. Estado da arte e história da pesquisa em educação estatística em programas brasileiros de pós-graduação. Campinas, SP: 2015. Originalmente apresentada como tese de doutorado, Universidade Estadual de Campinas, 2015.

SCHEAFFER, R. The ASA-NCTM Quantitative Literacy Project: An Overview. In: INTERNATIONAL CONFERENCE ON TEACHING STATISTICS, 3, 1990, New Zealand. Anais... Dunedin: New Zealand, 1990. p. 45-49.

SILVA, D. B. Analisando a transformação entre gráficos e tabelas por alunos do $3^{\circ}$ e $5^{\circ}$ ano do ensino fundamental. Recife, PE: 2012. Originalmente apresentada como dissertação de mestrado, Universidade Federal de Pernambuco, 2012.

SILVA, M. B. E. da. Aprendendo a representar escalas em gráficos: um estudo de intervenção. Recife, PE: 2014. Originalmente apresentada como dissertação de mestrado, Universidade Federal de Pernambuco, 2014.

SOARES M. B; MACIEL, F. Alfabetização. Brasília: MEC/Inep/ Comped, 2000.

STELMASTCHUCK, A. H. C. Probabilidade: significados atribuídos por alunos do ciclo II do ensino fundamental. Curitiba, PR: 2009. Originalmente apresentada como dissertação de mestrado, Universidade Federal do Paraná, 2009. 